\title{
Perceval Sutureless valves in isolated and concomitant AVR procedures: an economic model shows overall decrease of costs for isolated or combined operations
}

\author{
Lorenzo Pradelli ${ }^{1}$, Orietta Zaniolo ${ }^{1}$ \\ AdRes, Health Economics \& Outcomes Research, Turin
}

\begin{abstract}
Background: aortic valve replacement (AVR) the most common heart valve operation, accounts for a majority of all valve surgery performed in the elderly. The Perceval S (P) is a new aortic valve which is implanted without suturing, which causes a significant reduction in cross-clamping times (CCTs), and makes valve implantation easier and faster thanks to its collapsed profile. These features potentially allow the pool of operable patients to be expanded, even with minimally invasive surgery in isolated AVRs.

Aim: to predict costs and outcomes of AVR procedures associated with this new valve in 4 European countries (Italy, France, Germany, and UK), as compared to traditional (T) valve implants, from the cost perspective of the hospital.

Method: a probabilistic, patient-level simulation model was fully coded in WinBugs, permitting a seamless integration of parameter estimation and outcomes prediction, which was entirely based on the associated CCTs and on the surgical technique (mini-invasive [MiS] vs. full sternotomy [FS]), through published correlations. Unit cost were retrieved from official and literature sources for all countries. Besides the incorporated probabilistic sensitivity analysis, a series of deterministic sensitivity analyses was performed.

Results: the model predicts the use of the Perceval S valve to be associated with less complications and with savings (valve cost excluded), mainly related to a reduction in surgery costs and ICU/hospital bed days. These savings range from $€ 3,600$ (Italy) to $£ 3,900$ (UK) for PFS in isolated AVRs and from about $€ 6,000$ (Italy) to $£ 6,700$ (UK) for PMiS in isolated AVRs, and for PFS in concomitants. Extensive sensitivity analyses confirm the robustness of such findings.

Conclusions: the results of the present analysis indicate that the hospital acquisition cost difference between the new sutureless Perceval $\mathrm{S}$ valve and traditional valves is offset by important savings in other cost items.
\end{abstract}

\section{Keywords}

Aortic valve replacement; Economic model; Perceval S

\section{INTRODUCTION}

Aortic stenosis is the most common valvular abnormality found in the United States [1] and its incidence is expected to increase due to the ageing patient population; as a matter of fact, the prevalence of moderateto-severe aortic stenosis increases from $2.5 \%$ at 75 years of age to $8.1 \%$ at 85 [2]. Aortic valve replacement (AVR) is the most common form of heart valve operation and accounts for $60-70 \%$ of all valve surgery performed on the elderly. In adults with severe, symptomatic, calcific aortic stenosis, AVR is the first choice treatment and usually leads to an improvement in symptoms, functional status and survival. The 2006 American College of cardiology (ACC)/American Heart Association (AHA) guidelines have made a Class I recommendation for AVR in symptomatic patients with severe aortic stenosis [3]. AVR is also recommended, in certain circumstances, for patients with severe, asymptomatic aortic valve stenosis and for patients with mild-to-moderate aortic valve stenosis that undergo coronary artery bypass grafts $(\mathrm{CABG})$ as there is a significant possibility
Corresponding author Lorenzo Pradelli I.pradelli@adreshe.com

Disclosure

This study was funded by Sorin Group. 
that the evolution of the disease may require an AVR within the expected life time of the patient.

AVR carries an operative (30 days) mortality risk of $3.0-4.0 \%$ which increases to $5.0-7.0 \%$ when performed in association with a $\mathrm{CABG}$ operation $[1,3]$. However, this expected mortality rate may increase considerably where additional risk factors are present. Poor left ventricular systolic function increases the operative mortality risk to $8.0 \%-10 \%$ [4-7], and a recent study [8] highlighted an operative mortality rate of $6.5 \%$ in patients over 80 years of age.

Due to the presence of a high-risk profile, a significantly large subset of patients that present indications for valve surgery are deemed ineligible for conventional valve replacement because of these high-risk features or age [9]. One survey of 92 European heart centers found that 31.8 percent of patients with severe, symptomatic, single valve disease did not undergo intervention, most frequently because of comorbidities [10]. Prolonged aortic cross-clamping times (CCTs) are an independent risk factor for worse outcomes both in general cardiac surgery procedures $[11,12]$ and in isolated AVR, as has been recently confirmed by the work of Ranucci et al. [13] on a sample of over 3,000 patients.

The Perceval $\mathrm{S}$ is a new aortic valve which is implanted without suturing, which causes a significant reduction in CCTs [14], and makes valve implantation easier and faster thanks to its collapsed profile. These features potentially allow the pool of operable patients to be expanded, even with minimally invasive surgery (i.e. surgery performed with only a small incision, whether it be a right thoracotomy or a mini-sternotomy). It is known from the literature that this kind of approach is associated with less trauma and faster recovery, but also that it is associated with increased technical difficulty, when used with traditional valves, due to the need to operate in a very limited space. This has led to the very low uptake of this approach, which the availability of sutureless valves may overcome $[15,16]$. As is common for innovative technologies, the purchasing price of Perceval S is higher than traditional valves. This extra cost, however, may be partially or totally offset by savings on other components of care costs that a hospital treating a patient needing an AVR may accrue during (and after) his/ her hospital stay. Such costs may include operating theatre costs and the management of complications. The aim of the present simulation study is to comprehensively evaluate the cost of the main surgical alternatives for AVR in medium-to-high risk patients. Pro- cedural interventions (TAVI - Transcatheter Aortic Valve Implantation) have not been considered in this study, as their scope is defined by surgical inoperability [17-19].

To this aim, a simulation model was built to estimate the effects of using different valves and surgical techniques on clinical outcomes, possible complications and related treatment costs.

\section{METHODS AND MATERIALS}

The probabilistic, patient-level simulation model was fully coded into WinBugs, an open-source software package for Bayesian statistical analysis.

The main surgical options available for patients that need AVR and are at mediumto-high surgical risk can be defined by the type of prosthesis implanted (sutureless vs. sutured) and the surgical approach to the ostium (full sternotomy [FS] vs. mini-invasive [MiS] techniques). For patients that concomitantly undergo further procedures together with AVR, the model considers only the FS technique as being relevant. This reflects current practice, as shown in the meta-analysis by Brown et al., in which only 44 out of over 2,000 MiS patients underwent concomitant procedures [20].

On this basis, there are 5 strategies evaluated in the present work; 3 for stand-alone procedures (the first for the traditional valve in full sternotomy, the second and third involve Perceval S, both in full sternotomy and in MiS. Traditional valves implanted using MiS have not been considered as this surgical procedure has failed to achieve success and widespread application in real practice due to its high complexity), and 2 for concomitant procedures (traditional valve and Perceval $\mathrm{S}$, only in FS).

\section{Clinical data sources}

Published, peer-reviewed literature was relied on to feed the clinical side of our model. The correlations between CCTs and clinical outcomes were derived from an ad-hoc study, by Al-Sarraf et al., published in 2010 [11]. Surgical-technique specific outcome rates for patients with low CCT were elaborated (details in the next section) based on three matched case-control studies (Table I).

Sharony et al. published a case-control study [21] of FS vs. MiS in which groups were matched according to a large number of clinically relevant variables, thus minimizing the risk of potential confounders contributing to or causing the observed differences. De Smet et al. [22] also compared the outcomes of aortic valve replacements that 
were performed either with MiS or FS in an institutional review of their surgical AVR series. Bakir et al. published a case-control MiS vs. FS study [23] conducted on over 500 patients, matched on 6 relevant clinical criteria; this study is deemed as of high-quality by published meta-analyses [16,20]. A critical step in the analysis was the choice of the data source for the attribution of CCT distributions to the considered valve/surgical approach combinations, since no head-to-head randomized controlled trials were available. It was, thus, necessary to rely on the paper by Folliguet et al. for Perceval S-associated CCTs, as this is the only large clinical study published that has evaluated all three relevant alternatives (FS isolated, FS concomitant, and MiS) for the sutureless valve [14]. A literature search identified a series by the surgical team of Glauber et al. [24] that reported on the implantation of both valve types and detailed surgical times for the sutureless valve that were very close to those observed for the corresponding technique in the Folliguet paper (37 and 34 minutes on average, respectively). These data were used for traditional valves implanted in isolated AVRs with a full sternotomy approach [24]. Finally, for traditional valves implanted in concomitant procedures, which Glauber has not reported on, data was taken from the surgical series published by McClure [25], which shows FS-isolated CCT distribution data that are broadly equivalent to those reported by Glauber for the same valve/approach/operation combination.

Table II summarizes these values and the corresponding calculated CCT zones distributions, which were again obtained by fitting gamma distributions to the observed data.

\begin{tabular}{|c|c|c|c|c|c|c|c|}
\hline Study & Comparison & Design & $\mathbf{N}$. & $\begin{array}{c}\begin{array}{c}\text { Age } \\
\text { (years) }\end{array} \\
\end{array}$ & $\begin{array}{l}\text { Gender } \\
(\% \text { male })\end{array}$ & Euroscore & $\begin{array}{l}\text { CCT } \\
(\mathrm{min})\end{array}$ \\
\hline \multirow[t]{2}{*}{ Sharony, 2003 [21] } & Traditional FS & \multirow[t]{2}{*}{ Case-control study } & 189 & $75(7)$ & 52 & - & $75(24)$ \\
\hline & Traditional MiS & & 189 & $75(6)$ & 51 & - & $78(22)$ \\
\hline \multirow[t]{2}{*}{ Bakir, 2006 [23] } & Traditional FS & \multirow{2}{*}{$\begin{array}{l}\text { Retrospective, single } \\
\text { centre, matched for } 6 \\
\text { criteria }\end{array}$} & 274 & $71(11)$ & 56 & - & $70(17)$ \\
\hline & Traditional MiS & & 232 & $69(9)$ & 51 & - & $62(17)$ \\
\hline \multirow[t]{2}{*}{ De Smet, 2004 [22] } & Traditional FS & \multirow{2}{*}{$\begin{array}{l}\text { Prospective and } \\
\text { retrospective arms; } \\
\text { single centre }\end{array}$} & 91 & $68(9)$ & 58 & $5.6(2.7)$ & $79(16)$ \\
\hline & Traditional MiS & & 100 & $70(12)$ & 48 & $6.0(3)$ & $79(16)$ \\
\hline \multirow[t]{3}{*}{ Folliguet, 2012 [14] } & Perceval MiS & \multirow{3}{*}{$\begin{array}{l}\text { Prospective, } \\
\text { international, } \\
\text { multicenter study }\end{array}$} & 45 & $79(5)$ & 32 & $8.8^{\#}(5.3)$ & $34(10)$ \\
\hline & Perceval FS isolated & & 115 & & & & $29^{\wedge}(12)$ \\
\hline & Perceval FS concomitant & & 48 & & & & $44(13)$ \\
\hline \multirow[t]{2}{*}{ Glauber, 2012 [24] } & Traditional FS isolated & \multirow{2}{*}{$\begin{array}{l}\text { Retrospective, } \\
\text { observational, } \\
\text { propensity score } \\
\text { matched study }\end{array}$} & 138 & $70(12)$ & 61 & $5.4^{\S}$ & $72(27)$ \\
\hline & Traditional RT & & 138 & $70(12)$ & 58 & $5.6^{\S}$ & $87(32)$ \\
\hline \multirow[t]{2}{*}{ McClure, 2010 [25] } & Traditional FS isolated & \multirow{2}{*}{$\begin{array}{l}\text { Institutional } \\
\text { prospective database }\end{array}$} & 372 & $74(9)^{*}$ & 55 & - & $75(27)^{\star}$ \\
\hline & $\begin{array}{l}\text { Traditional FS } \\
\text { concomitant }\end{array}$ & & 443 & & & & $98(32)^{*}$ \\
\hline
\end{tabular}

Table I. Main clinical studies considered - baseline patient parameters. Data are mean (SD), unless otherwise stated * SD elaborated based on SE; § Median; \# Logistic; ^ Elaborated by comparing data from total FS and total isolated procedures

\begin{tabular}{|c|c|c|c|c|c|}
\hline \multirow{2}{*}{ Strategy } & \multirow{2}{*}{$\begin{array}{c}\text { CCT }(\min ) \\
\text { Mean } \pm \text { SD }\end{array}$} & \multicolumn{3}{|c|}{ СCT zones (\%) } & \multirow{2}{*}{ Source } \\
\hline & & $<60 \min$ & $60-90 \mathrm{~min}$ & $>90 \mathrm{~min}$ & \\
\hline \multicolumn{6}{|c|}{ Isolated procedures } \\
\hline Traditional - FS & $72 \pm 27$ & 35 & 41 & 24 & Glauber, 2012 [24] \\
\hline Perceval - FS & $29 \pm 12$ & 98 & 2 & 0 & Folliguet, 2012 [14] \\
\hline Perceval - MiS & $34 \pm 10$ & 99 & 1 & 0 & Folliguet, 2012 [14] \\
\hline \multicolumn{6}{|c|}{ Concomitant procedures } \\
\hline Traditional - FS & $98 \pm 31$ & 10 & 34 & 56 & McClure, 2010 [25] \\
\hline Perceval - FS & $44 \pm 13$ & 87 & 12 & 1 & Folliguet, 2012 [14] \\
\hline
\end{tabular}

Table II. CCT distributions according to procedure, surgical approach and implanted valve 


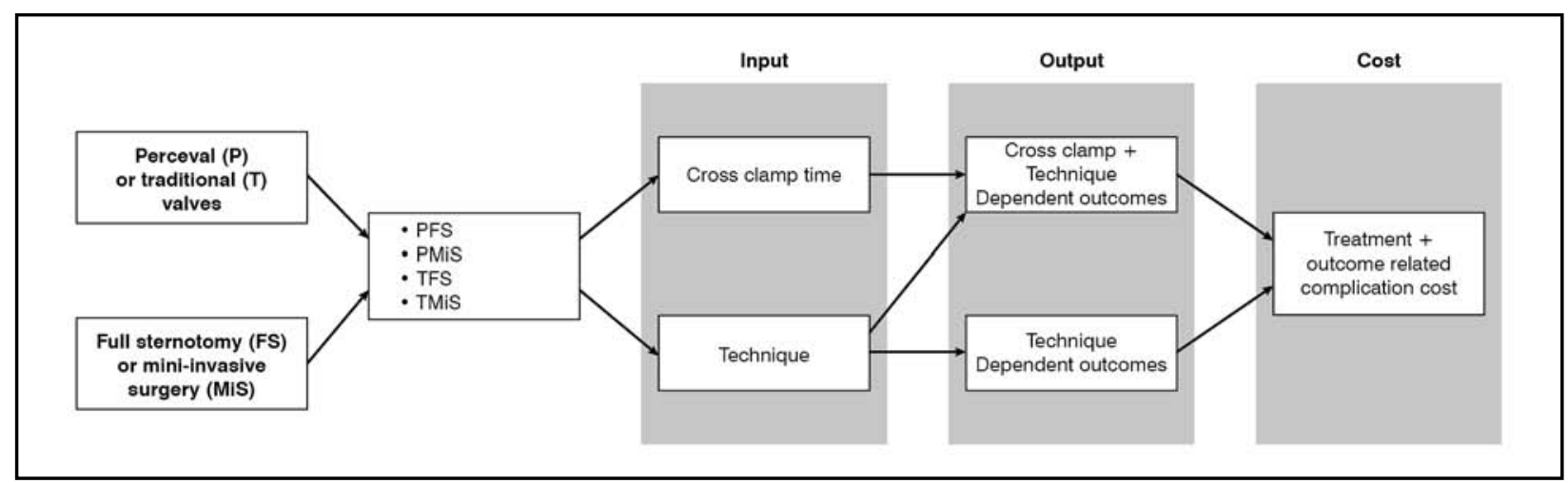

Figure 1. Graphical representation of the model structure

PFS = Perceval full sternotomy; PMiS = Perceval mini-invasive surgery; TFS = traditional full sternotomy; TMiS = traditional mini-invasive surgery

\begin{tabular}{|c|c|c|}
\hline \multirow{2}{*}{ Outcome } & \multicolumn{2}{|c|}{$\begin{array}{c}\text { RRs vs. CCT }<60 \text { min } \\
\text { Mean }(95 \% \mathrm{Cl})\end{array}$} \\
\hline & ССТ 60-90 min & $\mathrm{CCT}>90 \mathrm{~min}$ \\
\hline In-hospital mortality & $3.00(1.39-6.22)$ & $4.43(1.87-9.97)$ \\
\hline HLOS & $1.20(0.90-1.50)$ & $2.30(1.60-3.40)$ \\
\hline ICU stay & $1.30(1.00-1.60)$ & $3.00(2.00-4.60)$ \\
\hline Renal complications & $1.54(1.00-2.37)$ & $2.05(1.19-3.52)$ \\
\hline Blood transfusion & $1.05(0.94-1.23)$ & $1.60(1.36-1.77)$ \\
\hline Ventilation time & $1.47(0.81-2.44)$ & $3.42(1.92-5.65)$ \\
\hline
\end{tabular}

Table III. Modeled relationship between CCT strata and clinical outcomes, elaborated from Al-Sarraf et al. [11]

$\mathrm{CCT}=$ cross-clamping times, RRs $=$ relative risks, $\mathrm{HLOS}=$ hospital length of stay, $\mathrm{ICU}=$ intensive care unit

\begin{tabular}{lcc}
\hline \multicolumn{1}{c}{ Outcome } & FS & MiS \\
\hline Sepsis (\%) & 3.2 & 1.6 \\
Discharge to rehab (\%) & 75.1 & 44.5 \\
Conversion to FS (\%) & NA & $3 \%$ \\
\hline
\end{tabular}

Table IV. Values of CCT-unrelated parameters, according to the surgical approach, from Sharony et al. [21]

The model relies on the assumptions that AVR outcomes depend on (Figure 1):

- cross clamp time;

- surgical technique (full sternotomy or minimal invasive surgery).

In order to develop the model we followed these steps: a) the identification of the influence of CCT and technique on AVR outcomes; b) an estimation of CCT times for each alternative; c) the prediction of technique-dependant and CCT + technique dependant outcomes; d) a run and an analysis for the calibration and validation of the resulting model with published data; e) the construction of a cost structure that includes the surgery, the management of emerging adverse events (AEs), the hospital stay and all related resource consumption, and finally f) the run and full result analysis.

\section{Cross clamp time}

To identify which outcomes are significantly influenced by the CCT, we relied on the correlation study of CCTs and clinical outcomes published by Al-Sarraf in 2010 [11]. We were particularly interested in the cases of patients with a EuroScore of above 6 that confirmed a statistically significant association between at least one of the analyzed CCT categories ( $<60 \mathrm{~min}, 61-90 \mathrm{~min}$, and $>90 \mathrm{~min}$ ) and the following clinical outcomes: mortality, postoperative hospital length of stay (HLOS), ICU length of stay (ICULOS), renal complication rate, blood loss and bleeding rate, and ventilation time [11]. As can be seen in Table III, increasing CCT times are significantly associated with the worsening of several clinically and economically relevant outcomes, such as mortality, overall and ICU lengths of stay and the occurrence of complications. For the simulation, OR estimates (vs. reference, i.e. CCTs $<60 \mathrm{~min}$ ) reported by Al-Sarraf were transformed into relative risk (RR) distributions.

\section{Surgical techniques (full sternotomy or minimal invasive surgery)}

We identified outcomes that would depend on the surgical technique, but not on CCT, as those showing relevant differences in Sharony [21] which, however, are not influenced by CCT (according to Al-Sarraf [11]), i.e. sepsis rate and the need for rehabilitation.

The rate of permanent pace-maker implanting and stroke incidence, which were other initially considered outcomes, where later discarded as the literature reports controversial data for them. For our model, outcomes that only depend on the surgical approach are shown in Table IV.

\section{CCT + surgical technique}

To identify which outcomes depend both on $\mathrm{CCT}$ and surgical technique, we relied on the meta-analyses of Brown [20] and Murtuza [16] that compared MiS vs. FS. CCT-depen- 
dant outcomes (according to Al-Sarraf [11]). Those that were better with MiS despite increased CCT times were selected.

For these outcomes, the model estimated technique-specific rates for CCTs $<60 \mathrm{~min}$ $\left(\mathrm{R}_{\text {lowCCT }}-\right.$ Table $\left.\mathrm{V}\right)$ by decomposing overall observed rates $\left(\mathrm{R}_{\text {obs }}\right.$ - mean $\left.\pm \mathrm{SD}\right)$ using the RRs of Table III and the trial-reported distributions of CCTs for that rate, according to the general formula:

$\mathrm{R}_{\text {obs }}=\mathrm{R}_{\text {lowCCT }} \bullet \%_{\text {lowCCT }}+\mathrm{R}_{\text {lowCCT }} \bullet \%_{\text {mediumCCT }}$
$\cdot \mathrm{RR}_{\text {mediumCCT }}+\mathrm{R}_{\text {lowCCT }} \cdot \%_{\text {highCCT }} \cdot \mathrm{RR}_{\text {highCCT }}$

where $\%_{\mathrm{XCCT}}$ is the proportion of CCT times in the $\mathrm{X}$ category among the patient population contributing to the $\mathrm{R}_{\text {obs }}$, as estimated by WinBugs on the basis of the reported mean \pm $\mathrm{SD}$, assuming that these times follow a gamma distribution. An example using means only would be as follows: supposing it is known that a general population is made up of two groups, of which the relative numerousness (say, $\mathrm{A}=50, \mathrm{~B}=50$ ) and the relative risk of an event between them are known (say 1:2). The overall event rate was $30 \%$ and we would like to calculate the rate in the low risk group. By solving the equation Overall Rate $(30 \%)=\% \mathrm{~A} \cdot \mathrm{RiskA}+\% \mathrm{~B} \cdot \mathrm{RiskB}=0.5 \cdot$ RiskA $+0.5 \cdot \operatorname{RiskA} \cdot 2=1.5$ RiskA, we obtain RiskA $=20 \%$ and RiskB $=40 \%$.

Given the availability of the distributions for CCT zones per surgical alternative, $\mathrm{R}_{\text {lowCCT }}$ and $\mathrm{R}_{\text {lowXCCT }}$ for all CCT-depending outcomes, the model is able to perform a patient-level simulation by sampling a value for each parameter and predicting the individual outcome. For technique-only dependant outcomes, the simulation is simply based on the sampling of an individual value from the relative distribution for the pertinent technique.

\section{Validation}

In order to evaluate the predictive performance of the model, a series of internal and external validations were performed. The in-

\begin{tabular}{llll}
\hline \multicolumn{1}{c}{ Outcome } & \multicolumn{1}{c}{ FS } & \multicolumn{1}{c}{ MiS } & \multicolumn{1}{c}{ Source } \\
\hline HLOS (days) & $10.5 \pm 12.4$ & $8.4 \pm 9.1$ & Sharony, 2003 [21] \\
ICULOS (days) & $1.6 \pm 2.0$ & $1.2 \pm 1.4$ & De Smet, 2004 [22] \\
Blood loss in OP (ml) & $266 \pm 66$ & $280 \pm 68$ & De Smet, 2004 [22] \\
Blood loss in ICU (ml) & $359 \pm 83$ & $283 \pm 69$ & De Smet, 2004 [22] \\
Ventilator days & $1.0 \pm 3.7$ & $1.1 \pm 0.6$ & Bakir, 2006 [23] \\
$\begin{array}{l}\text { Incident dialysis (\%) } \\
\text { Re-operation for }\end{array}$ & $1.21 \pm 0.77$ & $1.95 \pm 1.03$ & Sharony, 2003 [21] \\
bleed (\%) & $4.39 \pm 1.57$ & $2.92 \pm 1.27$ & Sharony, 2003 [21] \\
\hline
\end{tabular}

Table V. Estimated values (mean $\pm S D$ ) for low CCT groups, according to surgical approach

HLOS = hospital length of stay; ICULOS = ICU length of stay

ternal validations consisted in comparing the model-predicted outcomes with the observed outcomes, using data from the studies on which the model is based. The external validations compared data observed in studies not involved in the modeling with model predictions obtained using only the information on CCTs and technique.

\section{Sensitivity analyses}

The probabilistic, patient-level simulation accounts for three types of uncertainty that are propagated throughout the model; the inter-individual variability among patients, uncertainty on parameter estimates (this is the reason for sampling from their full posterior distribution), and the intrinsic unpredictability of natural phenomena [26]. However, an extensive series of one-way sensitivity analyses has been incorporated to verify how influential the single modeled parameters are on the final cost estimate. These analyses are represented as tornado diagrams, in which the parameters are ranked in descending order of influence.

\section{Definition of costs}

The modeled costs structure, related to hospitalization for an AVR, is simplified in Figure 2 and implemented for the cost analysis

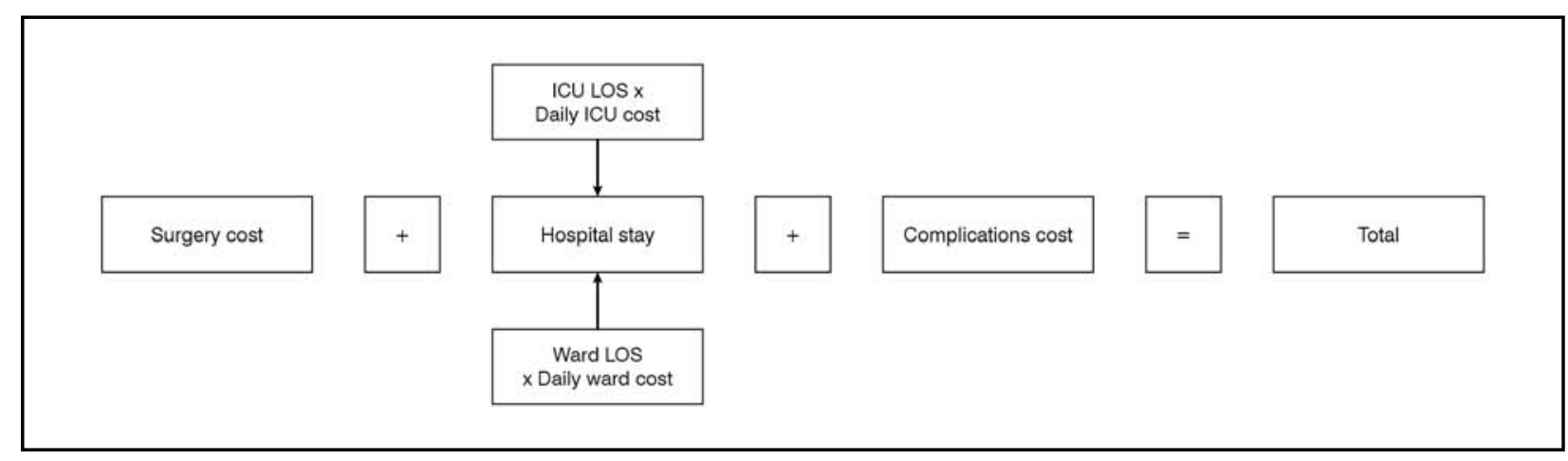

Figure 2. Graphical representation of the costs structure 
of the four European countries considered; Italy, Germany, France and the UK. Only the direct health care costs accrued for valve replacement and for the managing of complications were considered. All health care resources used during index hospitalization were included in hospital costs. All past costs were updated to 2011 (2012 only for Italian costs) values using official inflation indices $[27,28]$, while the most recent valid value has been used for tariffs.

\section{Surgery cost}

An approximate cost of the procedure is calculated based on the cost of the operating theatre, including materials cost, and the value of the labor of the health care personnel involved. It was decided to omit valve costs and focus on the difference that emerges from the consumption of other resources.

For this purpose, the following assumptions were made:

- The theatre was considered to be employed for a mean procedure time, common to all the procedure types (on average $130 \mathrm{~min}$ [16]), plus the CCT specific for each procedure, plus half an hour for room preparation/asepsis [29].

- Several health care professionals are involved during a procedure. The costs of 2 surgeons, 1 anaesthesiologist, one assistant anaesthesiologist, 1 instrumentalist, 1 perfusionist, one nurse and one health operator (for asepsis only) were considered in our analysis.
- The transfusion of a single red blood cell unit was considered for blood losses between $500 \mathrm{ml}$ and one liter, above which the transfusion of two units was taken into account.

- The impact of ventilation time was related to the development of ventilator-associated pneumonia, according to the cumulative incidence reported by VanHems et al. [30].

According to an analysis conducted on seven Italian operating rooms by an association of hospital medical directors, one minute of operating theatre use costs around $€$ 22 (2008 value) [31]. The same value was modeled for the French and German analyses because of a lack of specific information, whereas a mean cost/minute of $£ 20$ for the year 2009 was estimated in a UK project carried out by the NHS institute for innovation and improvement [32] and used in our study.

The unit cost for health personnel labor was estimated according to real hospital-borne costs for Italy, France, Germany and the UK [33-36].

An official blood bag tariff was taken as a proxy of the real cost for the collection, transportation and storage of patient blood [37-40]. The hospital cost of one autologous $\mathrm{RBC}$ unit (collection and storage) was considered for the UK analysis [41].

Unit costs, expressed as current prices, are detailed in Table VI.

\begin{tabular}{|c|c|c|c|c|c|c|c|c|}
\hline Parameters & Italy $(\boldsymbol{\epsilon})$ & Source & France $(€)$ & Source & Germany (€) & Source & UK (£) & Source \\
\hline Minute of OR & 23.50 & ANMDO [31] & 23.50 & $\begin{array}{c}\text { ANMDO } \\
{[31]}\end{array}$ & 23.50 & ANMDO [31] & 21.28 & NHS, 2009 [32] \\
\hline \multicolumn{9}{|c|}{ Health personnel costs (per minute) } \\
\hline Surgeon (x 2) & 1.28 & $\begin{array}{c}\text { Orrico, } 2007 \\
{[33]}\end{array}$ & 2.29 & $\begin{array}{l}\text { Bellamy, } \\
2010 \text { [34] }\end{array}$ & 0.96 & $\begin{array}{l}\text { Schreyögg, } \\
2006 \text { [35] }\end{array}$ & 1.38 & $\begin{array}{l}\text { Al-Ruzzeh, } \\
2008 \text { [36] }\end{array}$ \\
\hline Anaesthesiologist & 1.28 & $\begin{array}{c}\text { Orrico, } 2007 \\
{[33]}\end{array}$ & 2.65 & $\begin{array}{l}\text { Bellamy, } \\
2010 \text { [34] }\end{array}$ & 0.96 & $\begin{array}{c}\text { Schreyögg, } \\
2006 \text { [35] }\end{array}$ & 1.38 & $\begin{array}{l}\text { Al-Ruzzeh, } \\
2008 \text { [36] }\end{array}$ \\
\hline Assistant & 1.28 & $\begin{array}{c}\text { Orrico, } 2007 \\
{[33]}\end{array}$ & 2.65 & $\begin{array}{l}\text { Bellamy, } \\
2010[34]\end{array}$ & 0.96 & $\begin{array}{l}\text { Schreyögg, } \\
2006 \text { [35] }\end{array}$ & 1.38 & $\begin{array}{l}\text { Al-Ruzzeh, } \\
2008 \text { [36] }\end{array}$ \\
\hline Instrumentalist & 0.44 & $\begin{array}{c}\text { Orrico, } 2007 \\
{[33]}\end{array}$ & 0.68 & $\begin{array}{l}\text { Bellamy, } \\
2010 \text { [34] }\end{array}$ & 0.61 & $\begin{array}{c}\text { Schreyögg, } \\
2006 \text { [35] }\end{array}$ & 0.78 & $\begin{array}{l}\text { Al-Ruzzeh, } \\
2008 \text { [36] }\end{array}$ \\
\hline Perfusionist & 1.28 & $\begin{array}{c}\text { Orrico, } 2007 \\
{[33]}\end{array}$ & 2.65 & $\begin{array}{l}\text { Bellamy, } \\
2010[34]\end{array}$ & 0.96 & $\begin{array}{l}\text { Schreyögg, } \\
2006 \text { [35] }\end{array}$ & 0.95 & $\begin{array}{l}\text { Al-Ruzzeh, } \\
2008 \text { [36] }\end{array}$ \\
\hline Nurse & 0.44 & $\begin{array}{c}\text { Orrico, } 2007 \\
{[33]}\end{array}$ & 0.68 & $\begin{array}{l}\text { Bellamy, } \\
2010 \text { [34] }\end{array}$ & 0.61 & $\begin{array}{l}\text { Schreyögg, } \\
2006 \text { [35] }\end{array}$ & 0.78 & $\begin{array}{l}\text { Al-Ruzzeh, } \\
2008 \text { [36] }\end{array}$ \\
\hline Health operator & 0.32 & $\begin{array}{c}\text { Orrico, } 2007 \\
{[33]}\end{array}$ & 0.50 & $\begin{array}{l}\text { Bellamy, } \\
2010 \text { [34] }\end{array}$ & 0.27 & $\begin{array}{l}\text { Schreyögg, } \\
2006 \text { [35] }\end{array}$ & 0.13 & $\begin{array}{c}\text { Labour market } \\
\text { statistics [42] }\end{array}$ \\
\hline \multicolumn{9}{|l|}{ Transfusion } \\
\hline RBC unit & 153 & $\begin{array}{c}\text { Accordo } \\
\text { Stato-Regioni, } \\
2003 \text { [37] }\end{array}$ & 183.84 & $\begin{array}{l}\text { JORF, } \\
2012 \text { [43] }\end{array}$ & 105.53 & $\begin{array}{l}\text { Heimer, } 2010 \\
\text { [39]; KBV, } \\
2012[40]\end{array}$ & 172.76 & $\begin{array}{l}\text { Martinez, } \\
2007 \text { [41] }\end{array}$ \\
\hline
\end{tabular}

Table VI. Surgery section, unit costs 


\begin{tabular}{|c|c|c|c|c|c|c|c|c|}
\hline Parameters & Italy $(\boldsymbol{\epsilon})$ & Source & France $(€)$ & Source & Germany (€) & Source & UK (£) & Source \\
\hline Ward day & 411.71 & $\begin{array}{c}\text { Bartoli, } \\
2012 \text { [44] }\end{array}$ & 444.59 & $\begin{array}{l}\text { WHO- } \\
\text { CHOICE, } \\
2011 \text { [45] }\end{array}$ & 448.44 & $\begin{array}{l}\text { WHO- } \\
\text { CHOICE, } \\
2011 \text { [45] }\end{array}$ & 371.62 & $\begin{array}{l}\text { WHO- } \\
\text { CHOICE, } \\
2011 \text { [45] }\end{array}$ \\
\hline ICU day & $1,109.57$ & $\begin{array}{l}\text { Tarricone, } \\
2010 \text { [46] }\end{array}$ & $1,328.31$ & $\begin{array}{c}\text { Garrigues, } \\
2010 \text { [47] }\end{array}$ & $1,141.86$ & $\begin{array}{l}\text { Neilson, } \\
2004 \text { [48] }\end{array}$ & $1,703.72$ & $\begin{array}{l}\text { Edbrooke, } \\
2001 \text { [49] }\end{array}$ \\
\hline
\end{tabular}

Table VII. Hospital stay costs

\section{Hospital stay cost}

The total cost of a hospital stay was made up of the cost of the ICU in which the patient spends the days immediately after the surgical procedure plus the cost of the standard ward which hosts the patient after the critical post-operative phase has been completed.

For Italy, the cost per ward day was estimated according to a retrospective analysis of resources consumed by 87 patients hospitalized for TAVI (trans-catheter aortic valve implantation) (Ospedale Sant'Orsola di Bologna) [44]. It was decided to use an analysis conducted by the WHO for the other countries [45]. An ICU day cost was obtained from observational studies that are specific for each country, after cost items already included in the model were excluded [46-49]. Unit costs, expressed as current prices, are summarized in Table VII.

\section{Complications cost}

The events considered in the present analysis as linked to the surgical procedure and complicating the normal postoperative course are sepsis, renal failure, ventilator-associated pneumonia and bleeding that leads to re-operation. The possible prolongation of a hospital stay that derives from the onset of complications is already reflected in the overall mean LOS statistics. In order to avoid double counting, complications cost has been limited to the adjunctive diagnostic tests/procedures, drugs and extra materials needed for their management. Rehabilitation was also included in the complications cost section.

For all the countries, except Germany, the total adjunctive resource consumption due to the management of sepsis, with the exclusion of increased length of stay, was estimated as the difference in the mean cost per hospital day of a patient with sepsis and a patient without, multiplied by the average number of hospital days needed to manage the event $[46,50,51]$.

In Germany, a bottom-up approach study into the cost per severe sepsis episode has been published [52]. According to the type of patients simulated in the present analysis, we adopted the value estimated for the surgical patients subgroup of the entire cohort enrolled in the study.

The cost of hospital haemodialysis treatment was included as a complication cost for patients that developed renal failure. The real costs of two kinds of procedure (continuous and intermittent hemodialysis) were used for Italy [53]. Hospital dialysis session tariffs were used as a proxy for hospital-borne cost for the other countries, and a frequency of 3 sessions per week was assumed $[40,43,54]$.

USA data were used to estimate the cost of hospital-acquired pneumonia for Italy and the UK, because of a lack of detailed data pertaining to these countries that would permit an episode cost excluding the cost an increased LOS to be calculated [55]. VAP cost in France and the UK was estimated via country-specific cost analyses [56,57].

The cost of re-operation because of bleeding was assumed to be equal to mean procedure time, with CCT and asepsis times excluded (160 minutes), multiplied by the cost per minute of operating health personnel and room use. Finally, the cost for rehabilitation was approximated using current tariffs for reha-

\begin{tabular}{|c|c|c|c|c|c|c|c|c|}
\hline Parameters & Italy (€) & Source & France $(€)$ & Source & Germany $(€)$ & Source & UK (£) & Source \\
\hline Sepsis episode & $2,060.86$ & $\begin{array}{l}\text { Tarricone, } \\
2010 \text { [46] }\end{array}$ & $3,723.43$ & $\begin{array}{l}\text { Brun-Buisson, } \\
2003 \text { [50] }\end{array}$ & $3,264.30$ & $\begin{array}{c}\text { Moerer, } \\
2002 \text { [52] }\end{array}$ & $7,768.83$ & $\begin{array}{l}\text { Plowman, } \\
2001 \text { [51] }\end{array}$ \\
\hline Dialysis H day & 311.31 & $\begin{array}{c}\text { Vitale, } 2003 \\
\quad[53]\end{array}$ & 154.20 & $\begin{array}{c}\text { JORF, } 2012 \\
{[43]}\end{array}$ & 74.29 & $\begin{array}{c}\text { KBV, } \\
2012 \text { [40] }\end{array}$ & 68.42 & $\begin{array}{l}\text { Department } \\
\text { of Health [54] }\end{array}$ \\
\hline VAP episode & $8,095.63$ & $\begin{array}{c}\text { Kollef, } 2012 \\
\text { [55] }\end{array}$ & 12,818 & $\begin{array}{l}\text { Lepelletie, } \\
2004 \text { [56] }\end{array}$ & $4,664.32$ & $\begin{array}{l}\text { Wilke, } \\
2011 \text { [57] }\end{array}$ & $6,686.35$ & $\begin{array}{c}\text { Kollef, } \\
2012 \text { [55] }\end{array}$ \\
\hline $\begin{array}{l}\text { Rehabilitation } \\
\text { day }\end{array}$ & 261.41 & $\begin{array}{c}\text { TUC, } 2011 \\
{[58]}\end{array}$ & 261.78 & $\begin{array}{c}\text { JORF, } 2012 \\
{[43]}\end{array}$ & 290.29 & $\begin{array}{l}\text { G-DRG, } \\
2012 \text { [59] }\end{array}$ & 292.95 & $\begin{array}{l}\text { Department } \\
\text { of Health [60] }\end{array}$ \\
\hline
\end{tabular}

Table VIII. Complications cost

$\mathrm{VAP}=$ ventilation associated pneumonia 
bilitation services in the 4 countries. Given the considered time horizon and guideline recommendations for post-cardiac surgery rehabilitation, this service was set at 20 days. Unit costs expressed as current prices are presented in Table VIII.

\section{RESULTS}

The internal validation series indicates that the model is satisfactorily capable of replicating observed data (Figure 3).

The external validation shows acceptable model prediction capabilities. Even when predicted values are not particularly similar to the central estimate (mean or median, depending on the outcome), the observed data are always well within the predicted $95 \%$ CI (Figure 4).

The results of the simulations, obtained with 20,000 iterations of the model after discard- ing the first 20,000 run-in iterations, are shown in Table VIII and in Table IX.

For isolated procedures, the model predicts that the total costs (net of valve) are considerably lower on average when a Perceval S valve is implanted using mini-invasive techniques than when a traditional, sutured valve is implanted using the full sternotomy approach. The comparison of the cost figures of the three considered valve/surgical approach combinations highlights that a conspicuous part of the potential saving is related to the overcoming of the need for suturing (comparison between TFS and PFS), and that another, also significant, amount can be saved by switching to the less invasive surgical approaches. The amount and relative importance of the attainable savings depend on the local setting, although the absolute estimated figures are quite consistent across the

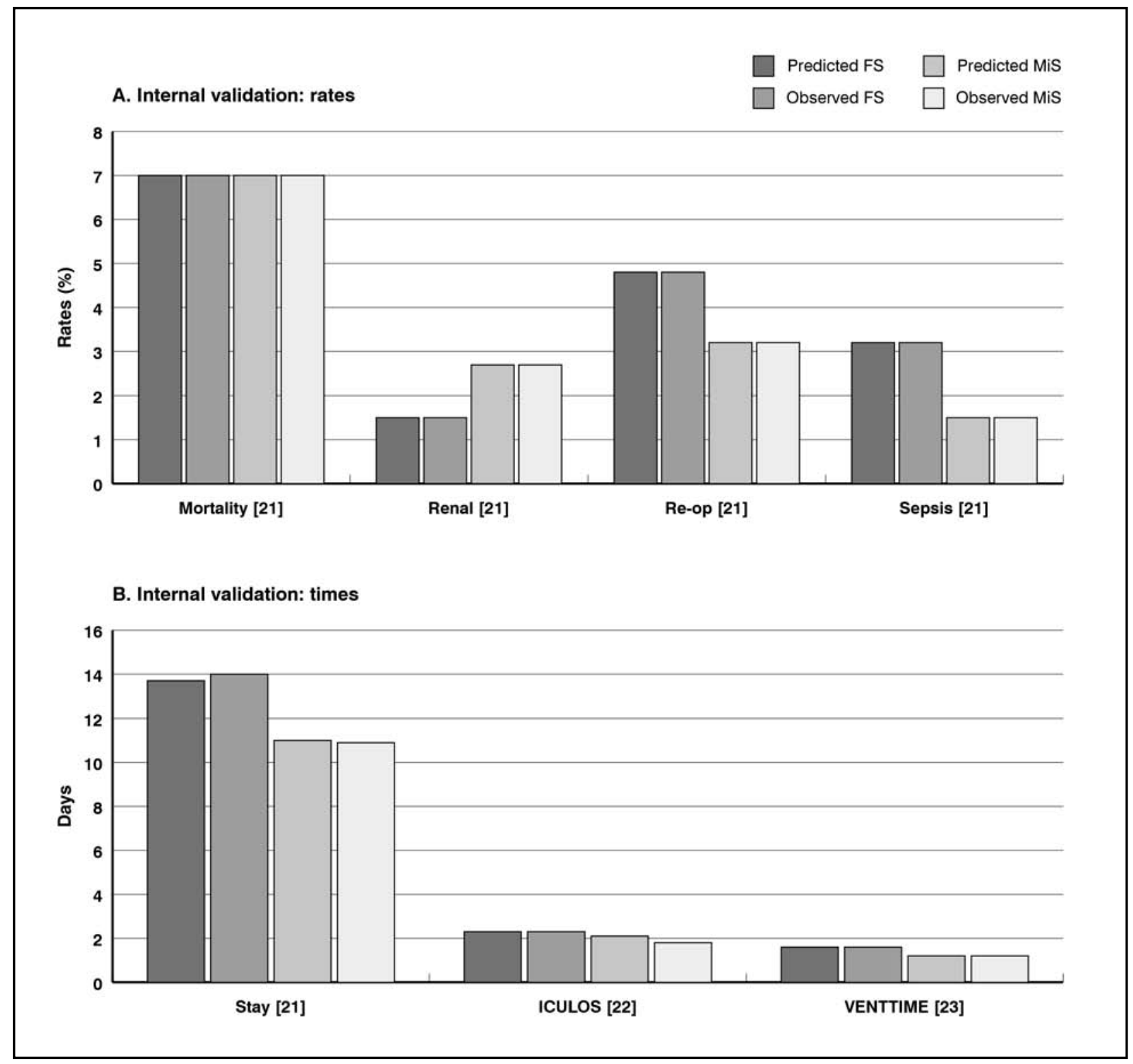

Figure 3. Results of internal validations on rates (A) and LOSs (B) 


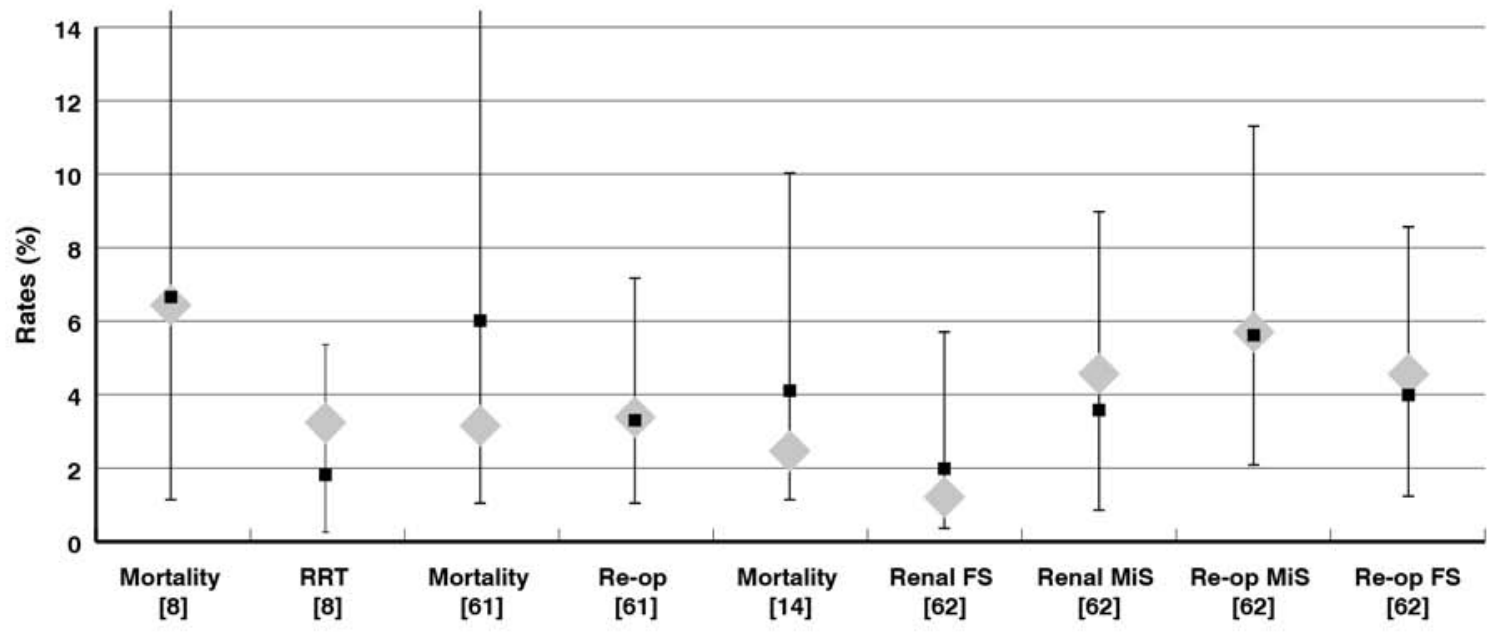

B. External validation: ICULOSs and BUs

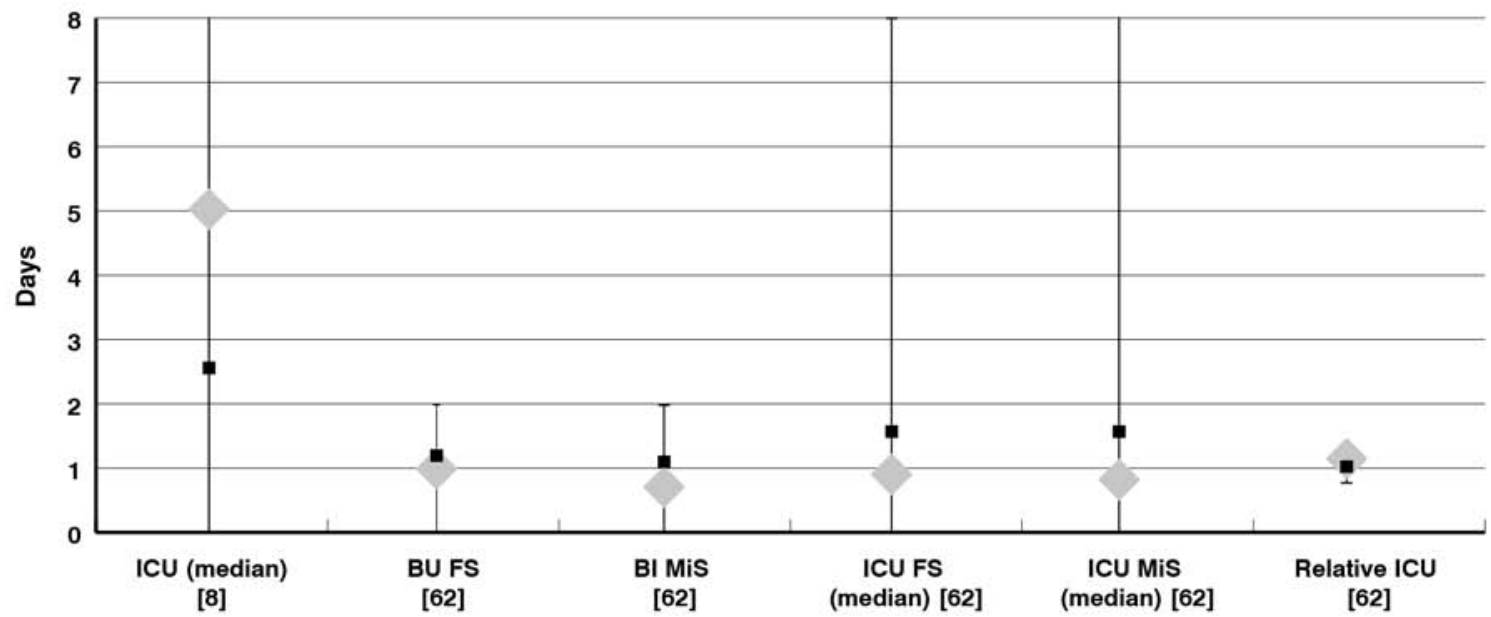

Figure 4. Results of external validation on rates (A), ICU lengths of stay and transfused blood units (B)

\begin{tabular}{lcccccccc}
\hline & V/SA & Surgery & Ward & Rehabilitation & ICU & Complications & Total & Delta* \\
\hline Italy (€) & TFS & $7,201(871.4)$ & $4,937(1,443)$ & $3,925(164.4)$ & $3,365(4,271)$ & $352.8(145)$ & $19,780(5,512)$ & - \\
& PFS & $5,855(384.2)$ & $3,723(140.8)$ & $3,925(164.4)$ & $2,362(2,086)$ & $280.3(80.33)$ & $16,150(2,190)$ & $3,602(66.42)$ \\
& PMiS & $5,891(297.7)$ & $3,298(39.94)$ & $2,326(190.4)$ & $2,057(1,561)$ & $238.8(79.13)$ & $13,810(1,631)$ & $5,970(63.53)$ \\
France & TFS & $8,589(1,057)$ & $5,331(1,559)$ & $3,930(164.7)$ & $4,029(5,112)$ & $426.4(137.5)$ & $22,310(6,455)$ & - \\
$(€)$ & PFS & $6,956(466.1)$ & $4,021(152.1)$ & $3,930(164.7)$ & $2,828(2,497)$ & $368.9(101.8)$ & $18,100(2,611)$ & $4,164(71.54)$ \\
& PMiS & $7,002(361.2)$ & $3,561(43.13)$ & $2,329(190.7)$ & $2,462(1,869)$ & $288.4(92.56)$ & $15,640(1,942)$ & $6,663(74.45)$ \\
Germany & TFS & $6,932(835.5)$ & $5,377(1,572)$ & $4,359(182.6)$ & $3,463(4,395)$ & $259.7(79.56)$ & $20,390(5,637)$ & - \\
$(€)$ & PFS & $5,641(368.4)$ & $4,056(153.4)$ & $4,359(182.6)$ & $2,431(2,147)$ & $229.1(62.91)$ & $16,720(2,611)$ & $3,641(67.15)$ \\
& PMiS & $5,676(285.4)$ & $3,592(43.5)$ & $2,583(211.4)$ & $2,116(1,607)$ & $166.7(57.24)$ & $14,130(1,663)$ & $6,257(65.05)$ \\
UK (£) & TFS & $6,813(828.9)$ & $4,456(1,303)$ & $4,398(184.3)$ & $5,167(6,557)$ & $483.9(142.1)$ & $21,320(7,523)$ & - \\
& PFS & $5,533(365.5)$ & $3,361(127.1)$ & $4,398(184.3)$ & $3,627(3,203)$ & $441.1(124.8)$ & $17,360(2,611)$ & $3,915(74.71)$ \\
& PMiS & $5,568(283.2)$ & $2,976(36.05)$ & $2,607(213.4)$ & $3,158(2,397)$ & $299(106.4)$ & $14,610(2,447)$ & $6,711(87.17)$ \\
\hline
\end{tabular}

Table IX. Simulation results for isolated AVR procedures (Traditional FS vs Perceval MiS)

* Data presented as mean (SEM) vs. TFS

FS = full sternotomy; MiS = mini-invasive surgery; $\mathrm{P}=$ Perceval; $\mathrm{T}=$ traditional; $\mathrm{V} / \mathrm{SA}=$ valve/surgical approach 


\begin{tabular}{lcccccccc}
\hline & & Surgery & Ward & ICU & Rehabilitation & Complications & Total & Delta* \\
\hline Italy $(€)$ & T & $8,011(1,018)$ & $6,072(1,535)$ & $4,365(5,468)$ & $3,925(164.4)$ & $430.5(172.3)$ & $22,800(6,653)$ & $6,063(58.48)$ \\
& $P$ & $6,294(423.5)$ & $3,816(324.9)$ & $2,420(2,206)$ & $3,925(164.4)$ & $284.8(83.24)$ & $16,740(2,408)$ & \\
France $(€)$ & T & $9,572(1,235)$ & $6,557(1,658)$ & $5,226(6,546)$ & $3,930(164.7)$ & $492.6(154.4)$ & $25,780(7,823)$ & $6,968(68.27)$ \\
& P & $7,490(513.7)$ & $4,121(350.8)$ & $2,897(2,641)$ & $3,930(164.7)$ & $371.7(102.5)$ & $18,810(2,860)$ & \\
Germany (€) & T & $7,709(976.4)$ & $6,614(1,672)$ & $4,492(5,628)$ & $4,359(182.6)$ & $295.4(87.42)$ & $23,470(7,823)$ & $6,169(59.74)$ \\
& P & $6,063(406)$ & $4,156(353.9)$ & $2,491(2,270)$ & $4,359(182.6)$ & $230.5(63.11)$ & $17,300(2,860)$ & \\
\multirow{2}{*}{ UK $(£)$} & T & $7,584(968.7)$ & $5,481(1,386)$ & $6,703(8,397)$ & $4,398(184.3)$ & $535.5(151.3)$ & $24,700(7,823)$ & $6,748(77.57)$ \\
& P & $5,951(402.9)$ & $3,444(293.3)$ & $3,716(3,388)$ & $4,398(184.3)$ & $442.9(124.8)$ & $17,950(2,860)$ & \\
\hline
\end{tabular}

Table X. Simulation results for concomitant AVR procedures

* Data presented as mean (SEM)

$\mathrm{P}=$ Perceval; $\mathrm{T}=$ traditional

countries considered and range from almost $€ 6,000$ in Italy to slightly over $£ 6,700$ in the UK for the TFS vs. PMiS comparison, and from roughly $€ 3,600$ to about $£ 3,900$ for the PFS vs. PMiS comparison. The contribution of the different cost items to the overall saving is also variable across the countries, although the main cost difference drivers are ward stay, ICU stay, surgical procedure and rehabilitation, each contributing about a quarter in all analyzed settings. The relatively small standard error of the mean (SEM) difference indicates that these results are robust, as assessed by the probabilistic sensitivity analysis incorporated within the simulation.
For concomitant procedures, the overall predicted saving is similar to that estimated for PMiS vs. TFS in isolated procedures, although the contribution of the single cost items is quite different. The costs for rehabilitation do not contribute to the estimated differences, and consequently the effect of fewer bed days and shorter surgical procedures gain more relative importance. The uncertainty reflected in the probabilistic structure of the model can be seen in the very small SEM difference for concomitant procedures, as was the case for the isolated procedures.

The results of the deterministic sensitivity analyses for Italy are depicted in Figures 5-8.

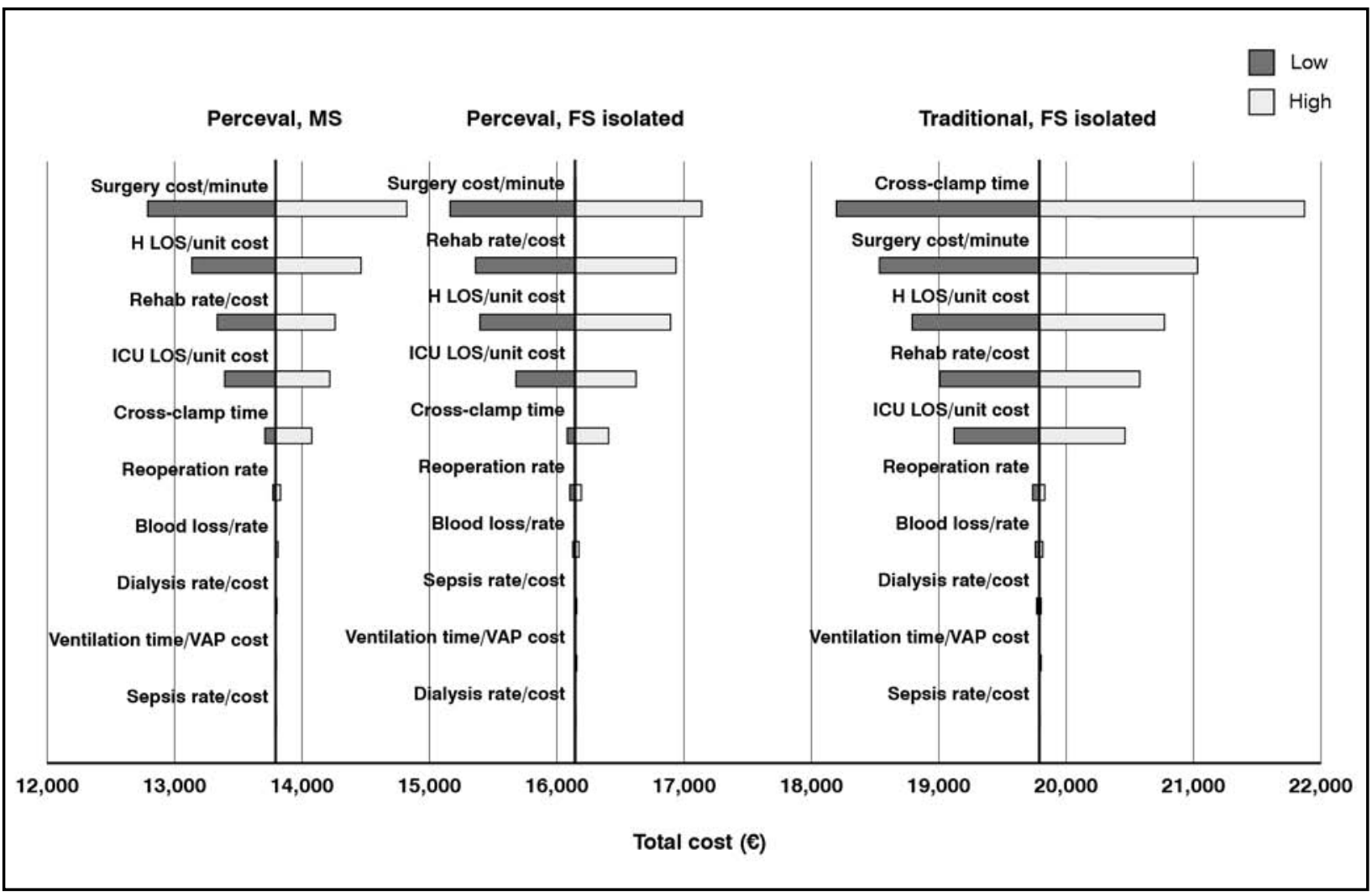

Figure 5. Tornado diagrams: one-way sensitivity analyses showing the influence of single parameters on the results for isolated AVRs 


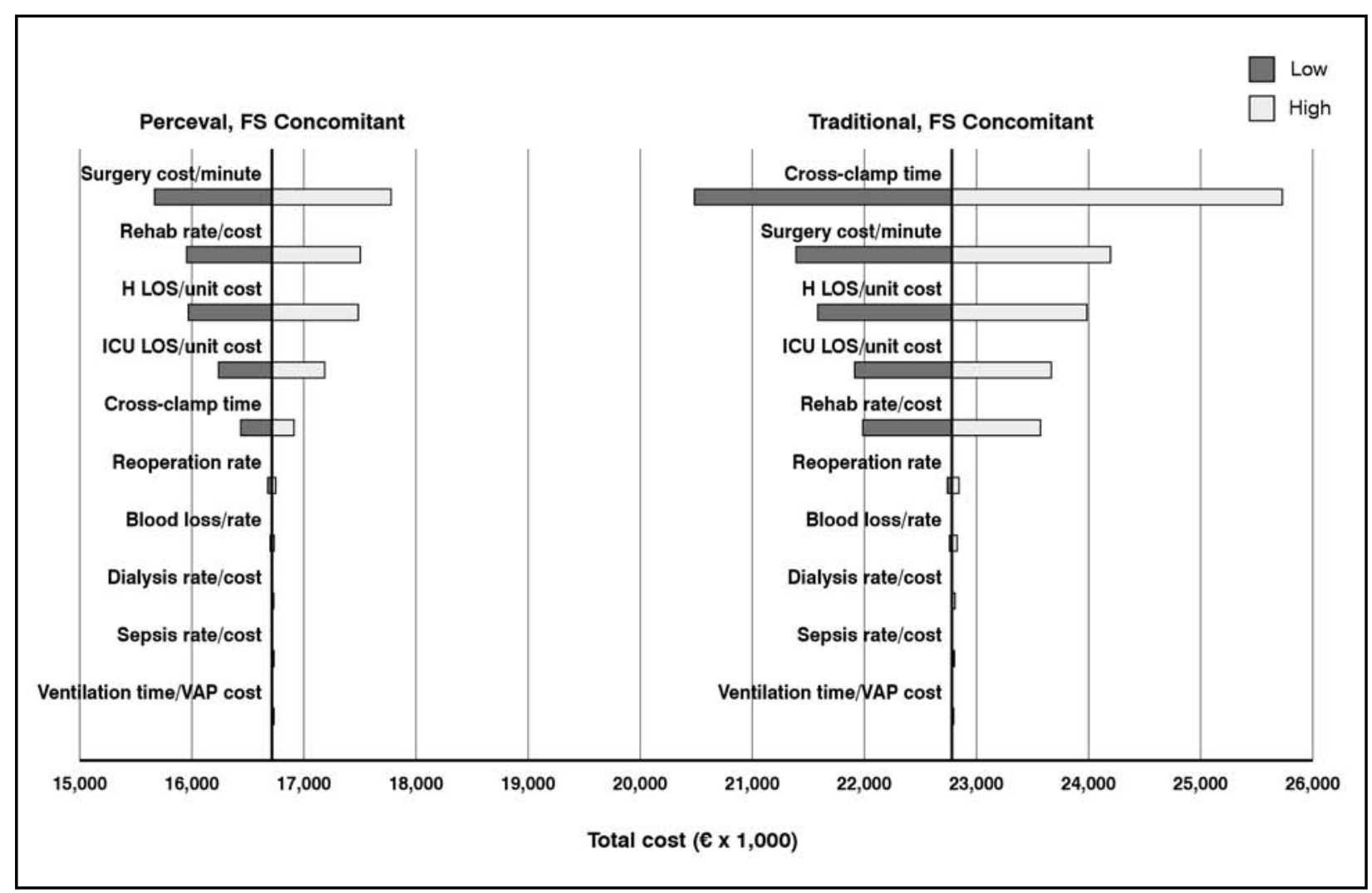

Figure 6. One-way sensitivity analysis showing the influence of single parameters on the results for concomitant procedures

One-way sensitivity analyses (Figure 5 and Figure 6) indicate that the total cost per Perceval case is most sensitive to the unit costs of the bed days in the ward and ICU, and to the cost of rehabilitation. The average cost per implantation of traditional valves is most sensitive to the aortic cross-clamp time. The mean cost of the alternative valve/approach combinations do not overlap for either isolated or concomitant procedures within the $+/-20 \%$ variation in any parameter.

Single parameter two-way sensitivity analyses (Figure 7 and Figure 8) were performed by concurrently worsening the estimate for Perceval by $20 \%$ and improving the same estimate for traditional by $20 \%$ (worst case), and vice versa (best case).

The estimated cost difference between TFS and PMiS in isolated AVRs ranges from about $€ 3,710$ (worst case - surgery cost per minute; $+20 \%$ for $\mathrm{P}$ while $-20 \%$ for T) to $€ 8,230$ (best case, opposite). In concomitant procedures, the estimated cost difference between $T$ and $P$ ranges from $€ 3,570$, in the hypothesis that CCTs of $\mathrm{P}$ are $20 \%$ higher than assumed and those of T $20 \%$ lower, and $€ 9,300$ in the opposite case.

\section{DISCUSSION}

Health economic evaluations aim at providing a rational trade-off between rising sani-

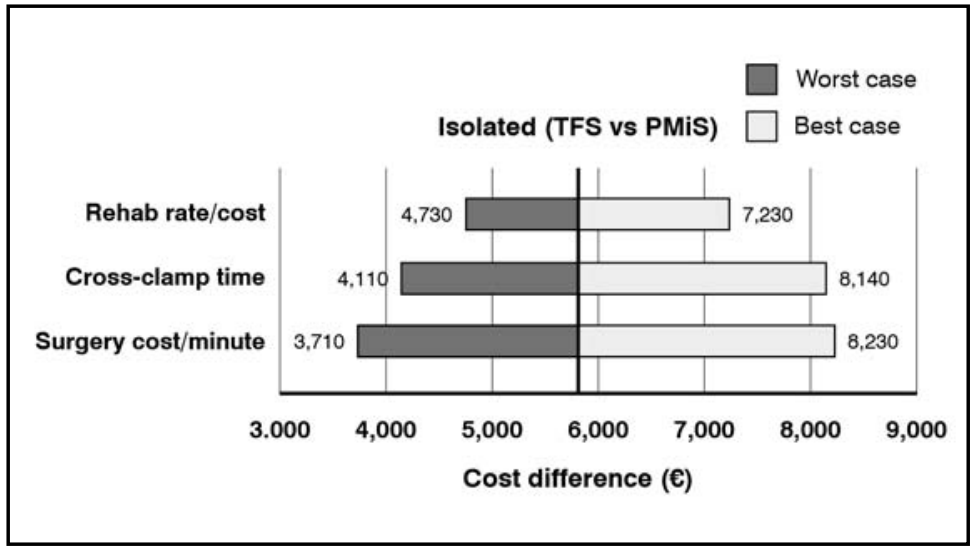

Figure 7. Two-way sensitivity analysis on the cost difference between TFS and PMiS. See text for explanation

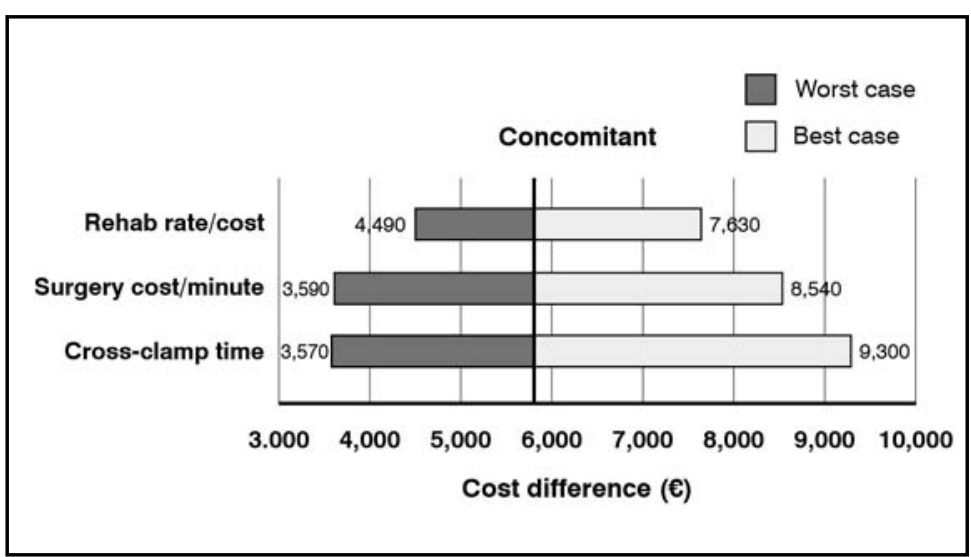

Figure 8. Two-way sensitivity analysis on the cost difference between traditional and Perceval in concomitant procedures. See text for explanation 
tary needs and the limited health care budget through the principle of efficient allocation of resources, and at valuing medical and technological innovation in terms of willingness to pay.

The assessment of the economics of an intervention, through pragmatic trials or observational studies, is a complex and expensive process which can take years or which, in some cases, is simply infeasible. However, health economics decisions have to be made, and "Such considerations (...) have led to the view held by some health economists that modeling in economic evaluation is an unavoidable fact of life" [63].

The present study proposes a cost analysis model based on the hypothesis that a reduction in CCT during the surgical replacement of a stenotic aortic valve may reduce the total cost of the procedure. This hypothesis is justified by the recent introduction of aortic valve bioprostheses (sutureless) that can be implanted in a shorter period of time, therefore decreasing the CCT.

The main result of this simulation model is that the use of sutureless aortic valve bioprostheses results in an overall decrease of costs in the range of $6,000-7,000$ Euros for both isolated and combined operations. Various items determine this cost saving, the most relevant being a reduction in surgery, ICU stay and ward stay costs.

Previous studies have highlighted that CCT is an independent risk factor for a number of postoperative complications in cardiac surgery, including low cardiac output and acute renal failure [11]. This leads to a direct and independent association of CCT with mechanical ventilation time and ICU and hospital stay duration [11]. It was observed that CCT has a direct impact on operative mortality for specific categories of patients; Flameng et al. [64] were able to demonstrate the existence of $1.8 \%$ increase in relative mortality risk per minute increase in CCT.

In the specific setting of surgical stenotic aortic valve replacement, Ranucci et al. [13] demonstrated that CCT is an independent predictor of a composite morbidity index (including low cardiac output, stroke, acute renal failure and mortality), with a relative increase in morbidity of $1.6 \%$ per minute CCT increase. Low cardiac output, stroke and acute renal failure are among the most common complications in cardiac surgery and consume considerable amounts of time and resources. The costs involved in this kind of complication are both direct (due to the use of specific devices, such as the intraaortic balloon pump, ventricular assist devices, hemofiltration/dialysis, etc.) and indirect (prolonged mechanical ventilation, ICU and hospital stay).

The present simulation study confirms that the expected reduction of morbidity rate obtained by reducing the CCT with sutureless valve implantation results in a considerable cost-saving, mainly due to a shortening of ICU and hospital stay.

The major limitation of the present study is the relatively small number of studies published in this area. Additionally, there are no randomized controlled studies to provide a high level of evidence. Due to these limitations, it is difficult to structure a model that takes into account the specific cost-savings related to a specific reduction in each morbidity event (stroke, acute renal failure, low cardiac output, etc.). However, both the ICU and the hospital stay may be considered as surrogates for "any kind of morbid events" which invariably prolong both these variables.

Modeling in health economics is intended to provide an abstraction process through a simplified simulation of the alternative interventions and their consequences, including multiple therapeutic decisions and relevant event probabilities, coupled with the associated resource consumption. The results of a model cannot, by any means, be regarded as an absolute effectiveness claim, but in their interpretation it should always be kept in mind that the objective of the analysis is the "comparative assessment" of cost and outcomes of two or more healthcare technologies evaluated "under the same set of assumptions" (i.e. the model). The results of our validation series confirm that this is also the case for the present model; comparisons between strategies systematically show the right direction and a close magnitude, although absolute estimates are not always very accurate. This is easily explained if one considers how other factors influence considered outcomes. Mortality is surely determined by individual features that are not included in the model, while lengths of stay are clearly also determined by organizational aspects, and not only by patient outcomes. But, as is inherent in the definition of independent variables, the effects of CCT and technique act on top of these baseline features, and this is reflected in our results.

Another limitation that is worth mentioning concerns the input data on the cross-clamp times that have been selected. Although great effort has been put into retrieving literature data that permit CCT distributions to be assigned to the alternatives based on clear and fair criteria, the absence of a surgical series that reports on all considered technique/ 
valve combinations performed by the same team may limit the reliability of these data to some extent. However, sensitivity analyses show that the conclusions are only affected to a limited extent by this uncertainty.

\section{CONCLUSIONS}

Despite some limitations that are inherent to simulation studies, the results of the present analysis indicate that the hospital acquisition cost difference between the new sutureless Perceval $\mathrm{S}$ valve and traditional valves is offset by important savings in other cost items. This cost saving is found in reduced CCTs and/or in the increased suitability of the valve in minimally invasive techniques which leads to shorter stays in the ICU and in the hospital as a whole, due a lower occurrence of complications.

\section{REFERENCES}

1. Dewey TM, Brown D, Ryan WH, et al. Reliability of risk algorithms in predicting early and late operative outcomes in high-risk patients undergoing aortic valve replacement. J Thorac Cardiovasc Surg 2008; 135: 180-7; doi: 10.1016/j.jtcvs.2007.09.011

2. Ambler G, Omar RZ, Royston P, et al. Generic, simple risk stratification model for heart valve surgery. Circulation 2005; 112: 224-31; doi: 10.1161/CIRCULATIONAHA.104.515049

3. Bonow RO, Carabello BA, Kanu C, et al. ACC/AHA 2006 guidelines for the management of patients with valvular heart disease: a report of the American College of Cardiology/American Heart Association Task Force on Practice Guidelines (writing committee to revise the 1998 Guidelines for the Management of Patients With Valvular Heart Disease): developed in collaboration with the Society of Cardiovascular Anesthesiologists: endorsed by the Society for Cardiovascular Angiography and Interventions and the Society of Thoracic Surgeons. Circulation 2006; 114: e84-e231; doi: 10.1161/CIRCULATIONAHA.106.176857

4. Powell DE, Tunick PA, Rosenzweig BP, et al. Aortic valve replacement in patients with aortic stenosis and severe left ventricular dysfunction. Arch Intern Med 2000; 160: 1337-41; doi: 10.1001/archinte.160.9.1337

5. Pereira JJ, Lauer MS, Bashir M, et al. Survival after aortic valve replacement for severe aortic stenosis with low transvalvular gradients and severe left ventricular dysfunction. J Am Coll Cardiol 2002; 39: 1356-63; doi: 10.1016/ S0735-1097(02)01759-X

6. Connolly HM, Oh JK, Schaff HV, et al. Severe aortic stenosis with low transvalvular gradient and severe left ventricular dysfunction: result of aortic valve replacement in 52 patients. Circulation 2000; 101: 1940-6; doi: 10.1161/01.CIR.101.16.1940

7. Pai RG, Varadarajan P, Razzouk A. Survival benefit of aortic valve replacement in patients with severe aortic stenosis with low ejection fraction and low gradient with normal ejection fraction. Ann Thorac Surg 2008; 86: 1781-9; doi: 10.1016/j.athoracsur.2008.08.008

8. Smith CR, Leon MB, Mack MJ, et al.; PARTNER Trial Investigators. Transcatheter versus surgical aortic-valve replacement in high-risk patients. $N$ Engl J Med 2011; 364: 2187-98; doi: 10.1056/NEJMoa1103510

9. Casserly IP, Kapadia SR. Advances in percutaneous valvular intervention. Expert Review of Cardiovascular Therapy 2005; 3: 143-58; doi: 10.1586/14779072.3.1.143

10. Iung B, Baron G, Butchart EG, et al. A prospective survey of patients with valvular heart disease in Europe: The Euro Heart Survey on Valvular Heart Disease. European Heart Journal 2003; 24: 1231-43; doi: 10.1016/S0195$668 \mathrm{X}(03) 00201-\mathrm{X}$

11. Al-Sarraf N, Thalib L, Hughes A, et al. Cross-clamp time is an independent predictor of mortality and morbidity in low- and high-risk cardiac patients. Int J Surg 2011; 9: 104-9; doi: 10.1016/j.ijsu.2010.10.007

12. Nissinen J, Biancari F, Wistbacka JO, et al. Safe time limits of aortic cross-clamping and cardiopulmonary bypass in adult cardiac surgery. Perfusion 2009; 24: 297-305; doi: 10.1136/hrt.2008.158709

13. Ranucci M, Frigiola A, Menicanti L, et al; for the Surgical and Clinical Outcome Research (SCORE) Group. Aortic cross-clamp time, new prostheses, and outcome in aortic valve replacement. Journal of heart valve diseases 2012 [in press]; doi: 10.1016/j.athoracsur.2012.04.042

14. Folliguet TA, Laborde F, Zannis K, et al. Sutureless perceval aortic valve replacement: results of two European centers. Ann Thorac Surg 2012; 93: 1483-8; doi: 10.1016/j.athoracsur.2012.01.071

15. Rosengart TK, Feldman T, Borger MA, et al. Percutaneous and Minimally Invasive Valve Procedures: A Scientific Statement From the American Heart Association Council on Cardiovascular Surgery and Anesthesia, Council on 
Clinical Cardiology, Functional Genomics and Translational Biology Interdisciplinary Working Group, and Quality of Care and Outcomes Research Interdisciplinary Working Group. Circulation 2008; 117: 1750-67; doi: 10.1161/ CIRCULATIONAHA.107.188525

16. Murtuza B, Pepper JR, Stanbridge RD, et al. Minimal Access Aortic Valve Replacement: Is It Worth It? Ann Thorac Surg 2008; 85: 1121-31; doi: 10.1016/j.athoracsur.2007.09.038

17. HAS (Haute Authoritè de Santè). Réévaluation des bioprothèses valvulaires aortiques implantées par voie artérielle transcutanée ou par voie transapicale. October 2011

18. NICE interventional procedure guidance 421. Transcatheter aortic valve implantation for aortic stenosis. March 2012; doi: 10.5220/0003771302010206

19. Santoro G, Vitali E, Tamburino C, et al. Impianto transcatetere di protesi valvolare aortica in pazienti con stenosi valvolare severa sintomatica. Documento di Consenso Federazione Italiana di Cardiologia (FIC) - Società Italiana di Chirurgia Cardiaca (SICCH). G Ital Cardiol 2010; 11: 45-53

20. Brown ML, McKellar SH, Sundt TM, et al. Ministernotomy versus conventional sternotomy for aortic valve replacement: a systematic review and meta-analysis. J Thorac Cardiovasc Surg 2009; 137: 670-9; doi: 10.1016/j. jtcvs.2008.08.010

21. Sharony R, Grossi EA, Saunders PC, et al. Minimally invasive aortic valve surgery in the elderly: a case-control study. Circulation 2003; 108 Suppl 1: 43-7; doi: 10.1161/01.cir.0000087446.53440.a3

22. De Smet JM, Rondelet B, Jansens JL, et al. Assessment based on EuroSCORE of ministernotomy for aortic valve replacement. Asian Cardiovasc Thorac Ann 2004; 12: 53-7

23. Bakir I, Casselman FP, Wellens F, et al. Minimally invasive versus standard approach aortic valve replacement: a study in 506 patients. Ann Thorac Surg 2006; 81: 1599-604; doi: 10.1016/j.athoracsur.2005.12.011

24. Glauber M, Miceli A, Gilmanov D, et al. Right anterior minithoracotomy versus conventional aortic valve replacement: A propensity score matched study. J Thorac Cardiovasc Surg 2012 [Epub ahead of print]; doi: 10.1016/j. jtcvs.2012.03.064

25. McClure RS, Narayanasamy N, Wiegerinck E, et al. Late outcomes for aortic valve replacement with the CarpentierEdwards pericardial bioprosthesis: up to 17-year follow-up in 1,000 patients. Ann Thorac Surg 2010; 89: 1410-6; doi: $10.1016 /$ j.athoracsur.2010.01.046

26. Drummond M, McGuire A (eds). Handling uncertainty in economic evaluations and presenting the results. New York: Oxford University Press, 2001: 172-214

27. ISTAT 2012. Indici nazionali dei prezzi al consumo per le famiglie di operai e impiegati - generale al netto dei tabacchi. Coefficienti per tradurre valori monetari dei periodi sottoindicati nel mese di Gennaio 2012. Available at: http://rivaluta.istat.it/Rivaluta/\# (Last accessed June 2012)

28. HICPs - Harmonized Indices of Consumer Prices - Health sector. Available at: Eurostat http://epp.eurostat.ec.europa. eu/portal/page/portal/hicp/data/database (Last accessed June 2012)

29. Aranha GTC, Vieira RW, Martins de Oliveira PP, et al. Identification of a statistical method as a quality tool: patient's length of stay in the operating room. Rev Bras Cir Cardiovasc 2009; 24: 382-90; doi: 10.1590/S010276382009000400019

30. Vanhems P, Bénet T, Voirin N, et al. Early-onset ventilator-associated pneumonia incidence in intensive care units: a surveillance-based study. BMC Infect Dis 2011; 11: 236; doi: 10.1186/1471-2334-11-236

31. ANMDO 2009. Availabel on http://www.auro.it/naz09/dia\%20anmdo\%20auro\%202009.pdf (Last accessed June 2012)

32. NHS - Institute for innovation and improvement. Improving quality and efficiency in the operating theatre. 2009. Available at: http://www.institute.nhs.uk/images//documents/Quality_and_value/Productive\%20Operating\%20 Theatre/Finance\%20leaflet.pdf (Last accessed June 2012)

33. Orrico D, Bonifati M, Boninsegna C. Analysis of costs of the Stroke Unit of Trento by ICD-IX 434 Code. Riv. It. Neurobiologia 2007; 53: 211-7

34. Bellamy V, Fréchou H. Les revenus libéraux des professionnels de santé. Document de travail, série sources et method. DREES, N¹6, 2012. Available at: http://www.drees.sante.gouv.fr/IMG/pdf/seriesource-method16-2.pdf (Last accessed June 2012)

35. Schreyögg J, Tiemann O, Stargardt T, et al. Health Basket Project: WP 9 Health Basket Project: WP 9, 2006. Available at: http://www.ehma.org/files/Project\%20report\%20WP9\%20Gesamt.pdf (Last accessed June 2012) 
36. Al-Ruzzeh S, Epstein D, George S, et al. Economic evaluation of coronary artery bypass grafting surgery with and without cardiopulmonary bypass: cost-effectiveness and quality-adjusted life years in a randomized controlled trial. Artif Organs 2008; 32: 891-7; doi: 10.1111/j.1525-1594.2008.00647.x

37. Recepimento dell'Accordo tra il Ministro della Salute, le Regioni e le Province Autonome di Trento e di Bolzano sul documento recante: "Aggiornamento del prezzo unitario di cessione del sangue e degli emocomponenti tra servizi sanitari pubblici”. 24 luglio 2003 - Regioni Lombardia, Emilia Romagna, Piemonte

38. JORF 2012. Journal Officiel de la Republique Francaise. Arrêté du 12 avril 2011 modifiant l'arrêté du 9 mars 2010 relatif au tarif de cession des produits sanguins labiles. Available at: http://www.hemovigilance-cncrh.fr/Textes/2011/ tarif-2011-psl.pdf (Last accessed June 2012); doi: 10.1051/dmbd/2011113

39. Heimer P. Die Blutspendedienste des Deutschen Roten Kreuzes in der Bundesrepublik Deutschland: Entwicklung, Struktur und Leistungen, Perspektiven. Haemotherapie 2010; 14: 4-15

40. KBV 2012. Einheitlicher Bewertungsmaßstab für ärztliche Leistungen (official reference costs for medical procedures). Available at: http://www.kbv.de/ebm2012/ebmgesamt.htm. Erstellt am 19.03.2012 (V. 7.1) (Last accessed June 2012)

41. Martinez V, Monsaingeon-Lion A, Cherif K, et al. Transfusion strategy for primary knee and hip arthroplasty: impact of an algorithm to lower transfusion rates and hospital costs. Br J Anaesth 2007; 99: 794-800; doi: 10.1093/ $\mathrm{bja} / \mathrm{aem} 266$

42. Labour market statistics (March 2012). Available at: http://www.ons.gov.uk/ons/rel/lms/labour-market-statistics/ march-2012/index-of-data-tables.html (Last accessed June 2012); doi: 10.1787/data-00046-en

43. JORF 2012. Journal Officiel de la Republique Francaise. Arrêté du 28 février 2012 (JO du 29 février) fixant pour l'année 2012 les éléments tarifaires mentionnés aux I et IV de l'article L. 162-22-10 du code de la sécurité sociale et aux IV et V de l'article 33 modifié de la loi de financement de la sécurité sociale pour 2004. Available at: http:// www.legifrance.gouv.fr/affichTexte.do?cidTexte=JORFTEXT000025413804\&fastPos=8\&fastReqId $=1583766758$ \&categorieLien=id\&oldAction=rechTexte (Last accessed June 2012); doi: 10.1787/9789264168565-9-fr

44. Bartoli S, Saia F, Marrozzini C et al. Il costo dell'innovazione nel trattamento della stenosi aortica: l'impianto transcatetere di protesi valvolare aortica. Giornale Italiano di Cardiologia 2012; 13: 50-8

45. WHO-CHOICE 2011. Econometric estimation of unit costs for France, Germany, UK. 2008. Available at: http:// www.who.int/choice/country/country_specific/en/index.html (Last accessed June 2012)

46. Tarricone R, Torbica A, Franzetti F, et al. Hospital costs of central line-associatedbloodstream infections and costeffectivenessof closed vs. open infusion containers. The case of Intensive Care Units in Italy. Cost Eff Resour Alloc 2010, 8: 8; doi: 10.1186/1478-7547-8-8

47. Garrigues B. Etude CRRéa: Evaluation médico-économique du Coût Réel d'une journée en RÉAnimation. Séminaire ENC 2, Décembre 2010. Available at: http://www.snmrhp.org/Data/ModuleGestionDeContenu/application/880.pdf (Last accessed June 2012)

48. Neilson AR et al. A new concept for DRG-based reimbursement of services in German intensive care units: results of a pilot study. Intensive Care Med 2004; 30: 1220-3; doi: 10.1007/s00134-004-2168-x

49. Edbrooke DL, Ridley SA, Hibbert CL, et al. Variations in expenditure between adult general intensive care units in the UK. Anaesthesia 2001; 56: 208-16; doi: 10.1046/j.1365-2044.2001.01716.x

50. Brun-Buisson C, Roudot-Thoraval F, Girou E, et al. The costs of septic syndromes in the intensive care unit and influence of hospital-acquired sepsis. Intensive Care Med 2003; 29: 1464-71; doi: 10.1007/s00134-003-1877-x

51. Plowman R, Graves N, Griffin MAS, et al. The rate and cost of hospital acquired infections occurring in patients admitted to selected specialities of a district general hospital in England and the national burden imposed. $J$ Hosp Infect 2001; 47: 198-209

52. Moerer O, Schmid A, Hofmann M, et al. Direct costs of severe sepsis in three German intensive care units based on retrospective electronic patient record analysis of resource use. Intensive Care Med 2002; 28: 1440-6; doi: 10.1007/s00134-002-1429-9

53. Vitale C, Bagnis C, Marangella M, et al. Cost analysis of blood purification in intensive care units: continuous versus intermittent hemodiafiltration. $J$ Nephrol 2003; 16: 572-9

54. Department of Health: NHS reference costs 2009-2010. Available at: http://www.dh.gov.uk/en/Publicationsandstatistics/Publications/PublicationsPolicyAndGuidance/DH_123459 (Last accessed June 2012)

55. Kollef MH, Hamilton CW, Ernst FR. Economic impact of ventilator-associated pneumonia in a large matched cohort. Infect Control Hosp Epidemiol 2012; 33: 250-6; doi: 10.1086/664049 
56. Lepelletier D, Ferréol S, Villers D, et al. Infections nosocomiales à Staphylococcus aureus résistant à la méthicilline en réanimation médicale polyvalente: facteurs de risque, morbidité et impact économique. Pathol Biol (Paris) 2004; 52: 474-9; doi: 10.1016/j.patbio.2004.06.002

57. Wilke MH, Grube RF, Bodmann KF. Guideline-adherent initial intravenous antibiotic therapy for hospital-acquired/ ventilator-associated pneumonia is clinically superior, saves lives and is cheaper than non guideline adherent therapy. Eur J Med Res 2011; 16: 315-23; doi: 10.1186/2047-783X-16-7-315

58. Tariffa Unica Convenzionale (TUC), 2011

59. G-DRG System 2012. Available at: http://www.g-drg.de/cms/G-DRG-System_2012 (Last accessed June 2012)

60. Department of Health. 2010-11 reference costs publication. Available at: http://www.dh.gov.uk/en/Publicationsandstatistics/Publications/PublicationsPolicyAndGuidance/DH_131140 (Last accessed June 2012)

61. ElBardissi AW, Shekar P, Couper GS, et al. Minimally invasive aortic valve replacement in octogenarian, high-risk, transcatheter aortic valve implantation candidates. J Thorac Cardiovasc Surg 2011; 141: 328-35; doi: 10.1016/j. jtcvs.2010.08.056

62. Ruttmann E, Gilhofer TS, Ulmer H. Propensity Score-Matched Analysis of Aortic Valve Replacement by MiniThoracotomy. The Journal of Heart Valve Disease 2010; 19: 606-614

63. Drummond M, O’Brien B, Stoddart G, et al. Methods for the Economic Evaluation of Health Care Programmes. New York: Oxford University Press, 2004; doi: 10.1111/j.1467-8462.2004.00304.x

64. Flameng WJ, Herijgers P, Szécsi J, et al. Determinants of early and late results of combined valve operations and coronary artery bypass grafting. Ann Thorac Surg 1996; 61: 621-8; doi: 10.1016/0003-4975(95)00970-1 